92nd Annual Meeting

of The American Phytopathological Society

August 13, 2000, New Orleans, Louisiana

\title{
Whither Plant Pathology?
}

\author{
Neal K. Van Alfen
}

Dean-College of Agricultural and Environmental Science, University of California, Davis 95616.

Plant pathology is not recognized as a core discipline of the life sciences; we are a group of scientists who have formed a loosely knit community because of our common interests in the diseases of plants. We approach our study of plant disease from different perspectives: some as life scientists interested in understanding the process of disease at the cellular, organismal, or other hierarchical levels, whereas others are interested in applying this knowledge to assure a reliable source of food and fiber for people. Consequently, there are many different futures for plant pathology.

Many of us have made it a hobby, particularly during this past year of the beginning of the new millennium, to peer into the proverbial crystal ball in an attempt to be seers. Some are expected to do this as part of our jobs, but we probably are not any better at seeing the future than are any of the other discussants around the coffee pot. With that disclaimer, I will share my sense of what issues face plant pathology in the next decades and describe the opportunities that these issues will provide to plant pathologists.

The past couple of decades have been the most exiting in history for life scientists. The rate at which we have been able to describe and understand living organisms are taxing the ability of libraries to hold and catalogue the published information. We publish orders of magnitude more pages of new information each year than we did 50 years ago. There was a time when a plant pathologist could be expected to know most of the literature of plant pathology. There are few today who could claim such a breadth of knowledge. In research, rather than synthesizing diverse bits of knowledge into an understanding of plant disease, we study fungal molecular biology, virology, or epidemiology as they relate to plant disease. Although many lament the changes, they are providing us with an exciting understanding of plant disease. The answers to so many of the questions that were formerly hotly debated are now easily accessible to all students. We have the tools to answer our questions and so we will continue to explore the workings of life and plant disease. The future is very bright because knowledge is valued by our society.

For those of us interested in the application of knowledge to detect, manage, and reduce the impact of plant disease, the future is less clear. This is not because of a reduced need for food and fiber in a world of plenty. Instead it is primarily because of political restraints to long-term solutions to the continuing problems of poverty and hunger. As a society, we are much more concerned about the threat of the diseases that affect us as well fed individuals than we are about the famine that affects the voiceless. The success of agricultural researchers in the past has removed the ageless fear of famine from the lexicon of the modern anxieties of wealthy nations. Today the term pestilence evokes an entirely different set of fears than it did in former times when there was

Publication no. P-2000-1112-010 little confidence in a secure food supply. We now worry about the health of individuals rather than masses. Thus, plant disease and with it the specter of famine, is not something that concerns the political leaders of wealthy nations.

Environmental impact of agriculture. Plant pathologists can prosper in these times of relative abundance of food, because there are some important issues that need attention from professionals with our background and training. Foremost among these is the genuine concern by educated citizens that mankind is permanently scarring the earth and squandering our rich biological heritage. Agricultural practices are often portrayed as significantly contributing to environmental problems. When organic pesticides were discovered they were hailed for their positive contributions to increased food production and the reduction of serious human diseases such as malaria. These same products today are considered by many to be environmental poisons and health hazards. Although these fears are felt by most plant pathologists to be seriously overstated, they are driving many public policy decisions. Because such popular changes in social and environmental ethics are likely to reduce our disease control options, there is a need for new disease control strategies that are based on intensive monitoring and knowledge of the agro-ecosystem. We have made significant strides in recent years in our understanding of the ecology of disease, but we are just beginning.

The challenge we are facing is that these changing environmental ethics coincide with rapid population growth. It is expected that within the next 50 years there will be approximately $50 \%$ more people on earth to feed, house, and clothe (1). Although few who have carefully examined the challenge of feeding this many more people are pessimistic about our ability to do so under the best of conditions, it cannot be done using our current technology without significant environmental impacts. It is also likely that political unrest and inefficiency will continue to significantly reduce food production on otherwise productive farmlands. We should not base our future planning on best-case assumptions. Clearly, much more research is needed to meet the food and fiber needs of our increasing populations under conditions of higher standards of environmental protection.

Invasive pests. The world is not only increasing in population, but also in affluence. Besides the obvious increased food diversity and quality expectations associated with wealth, mobility of people and goods also increases with affluence. More people than ever have the time and means to travel and to import goods from all over the world; with the people and goods come inadvertent hitchhikers. Political problems also contribute to large movements of people throughout the world. With the advent of air travel the potential for movement of pests has increased dramatically. Invasive pests are a significant threat to the status quo of our natural ecosystems, our health, and agriculture. Many of the most serious plant diseases have already been spread throughout the world, but 
there is still good reason to be very diligent in monitoring and excluding those diseases that are still endemic to limited geographic areas. Much of my personal research has focused on trying to reduce the impact of chestnut blight in North America. This disease is often used as the classroom example of the destructive ability of invasive pests. The American chestnut is on its way to extinction in its native range because of chestnut blight. To date, plant pathologists have been almost powerless to prevent the spread of this disease in North America or to protect the American chestnut from infection. Given our limitations in controlling some types of plant diseases, any calculation of our ability to feed even the current population of the world must consider the potential for disaster that some plant diseases offer.

The inadvertent movement of pests as a consequence of world commerce is a growing problem and will challenge scientists and policy makers even more in the future than it has in the past. One of the most effective means available to control plant disease is the quarantine. The challenge, however, for agricultural inspectors to detect pests hitchhiking in goods and luggage is enormous. The U.S. Department of Agriculture reported that in 1998 inspectors intercepted more than 10,000 shipments containing pests at international ports (2). The increase in volume of world trade makes our ability to detect pests in trade goods very difficult. The issue of phytosanitation in policy decisions regarding agricultural trade has been a very contentious one and will continue to be so as normal trade barriers fall. Plant pathologists must continue to play an important role in these discussions to assure that decisions are made based on sound science. Clearly, economic and political decisions will prevail, but plant pathologists must educate policy makers concerning the economic costs of pest introductions. We must also be proactive in assuring that modern detection methods are developed and used by agricultural inspectors.

Emergence of new diseases and disease epidemics. Emergence of new disease epidemics must be expected. One of the most important contributions of plant pathology research to science is the recognition that pests evolve at a rapid rate and that single gene changes can turn an obscure microbe into the cause of an epidemic. The southern corn blight epidemic of 1972 is an example of the vulnerability of our crops to such genetic changes. In this case, the introduction of the Texas male sterile gene into corn was the genetic change that resulted in the epidemic, but the genetic race between host and pathogen is fundamental in the interactions of host and pathogen. Some of these systems, such as stem rust of wheat, are so dynamic that we must be constantly vigilant and be prepared to introduce new resistance genes as the old ones are defeated by genetic changes in the population of the pathogen. The challenge for plant pathology is to be able to predict when such genetic changes will happen. Certainly with stem rust of wheat we breed wheat in anticipation of these changes. The difficulty is that our ability to predict is based on past experience. If the cycle of genetic change is longer than a few decades in length, we do not have the experience to anticipate and prepare for the change. Because a significant reduction in the supply of one of our primary food crops could result in food shortages and starvation, we must be prepared. Medical epidemiologists take these emerging disease threats very seriously and have developed a system to anticipate and monitor such emerging diseases. We do not have such capabilities to protect our food supply. I find it interesting that only with the threat of bioterrorism is thought being given to the vulnerability of our food supply to attack by pathogens. Although the treat of terrorist attack on our food supply is certainly a possibility, we know from experience that the greatest threat is from the natural evolution of pathogens. The topic of emerging diseases is one that has caught the public imagination with the advent of AIDS caused by HIV. Plant pathologists must be more proactive in educating the public that the treat of emerging human diseases is no different in principle than that of plant diseases, and the potential for human suffering in each case could be significant.
Agricultural biotechnology. The ability to genetically modify plants, animals, and microbes in precise ways using methods of molecular biology provides our best hope for meeting the food, fiber, and nutritional needs of the growing population of the world without further compromising the quality of our environment. Our capability now to genetically modify living organisms in precise and almost limitless ways has generated concern by some thoughtful individuals. Humans do not have a laudable history of using new technologies wisely, so there is concern by some people that we may do more damage with this new technology than we will good. Because this technology is so important for the future, we must assure that we do not compromise its long-term value by meeting short-term goals. Utilization of the technology will affect all aspects of plant pathology because it will form the basis of disease detection, monitoring, and classification as well as form the basis of new plant disease management strategies. Because the technology is so important we must respond thoughtfully and with consideration to those who fear it. It is better in the short run to be overly cautious in addressing fears and potential risks of the technology than to risk mistakes that could compromise future benefits because of public rejection of the technology. We cannot afford the equivalent of a Chernobyl or Three Mile Island type of environmental disaster because of hasty or unwise use of agricultural biotechnology. Those of us who are advocates of the technology do not anticipate any of the type of disasters that confronted the nuclear power industry, but we must listen thoughtfully to its critics.

During much of my career as a plant pathologist, technology has been a significant issue of division in our profession. We often classified ourselves by the technology that we used to study plant disease, i.e., biochemists/physiologists, breeders/geneticists, microbiologists, etc. With the advent of the molecular biology techniques, many of these distinctions are beginning to disappear. In the early years of our profession, the use of microscopes and microbial cultural techniques were so commonly used that distinctions based on use of technology would have little meaning to describe subdivisions of our profession. We are rapidly approaching the time when these new molecular technologies will be as equivalent in universal usage as the microscope and petri dish.

Challenges for The American Phytopathological Society. Our society by most standards is a very successful one. We have been very successful in our publishing business and have been able to grow in membership during a time when many other professional societies are declining in size. Our profession is experiencing change, however, so our society must continually reassess its purpose and goals. Probably the biggest changes are occurring in academic departments and in industry. Plant pathology as a discipline is healthy, but some of our academic departments are being reorganized to reflect changes in academic programs and priorities. This type of organizational change is not a threat. It is not the equivalent of buggy whip manufacturers going out of business because their product is no longer needed. Plant pathology as a discipline will probably be even more important in the future than in the past, but it may not be organized in colleges of agriculture as in the past. This should not be perceived as a threat but as an opportunity for our profession to have an even greater voice in the future.

Changes in industry are also very dynamic at the moment. Many see great opportunities for agricultural biotechnology in the future, but with difficult times for the next few years. The consolidation of agricultural biotechnology companies is occurring at the same time that they are being divested from their pharmaceutical parent companies. Pesticides are still major products for these companies, but they will play decreasing roles in the future as genetic resistance is incorporated into seeds and clones. There are many opportunities in these turbulent times for innovative plant pathologists.

Because changes occur in the organizations that employ plant pathologists, there will be an even greater need for our professional society to represent the views and vision of plant pathologists. Whereas communication between plant pathologists has 
often been strongly tied to our academic departments, there is a much greater need now for APS to assume this role entirely. The society must also find ways to reach members who are not in the large academic departments. In the past, most of our members were either directly or indirectly related to the major academic departments, so our society learned to depend on these departments for officer nominations and for committee member nominations. As our society explores new models of governance we must also explore new ways to engage a broader spectrum of our membership in the activities of the society. The role of the society in preserving the quality of our discipline has never been more important than it is now.

Whither plant pathology? This is an exciting time to be a plant pathologist. We are uncovering new knowledge at an as- tounding rate and have reached a level of understanding of life that the scientists of the past probably could not even imagine would be possible. This knowledge is coming at a time when it is needed to assure that we can provide the food and fiber needed for increasing numbers of people without destroying the natural things on this earth that bring us all joy. We have challenges and opportunities; it couldn't be any better than this.

\section{LITERATURE CITED}

1. Alexandratos, N. 1999. World food and agriculture: Outlook for the medium and longer term. Proc. Natl. Acad. Sci. USA 96:5908-5914.

2. Coppock, R. H., and Kreith, M. 1999. Exotic Pests and Diseases: Biology, Economics, Public Policy. Summary report of a conference sponsored by Agricultural Issues Center, University of California, Davis. 